Chemotherapy for advanced lung cancer

\section{Chemotherapy for advanced lung cancer: is the glass half full or half empty? \\ G Silvestri}

\section{Patients with advanced lung cancer should share in the decision whether or not to undergo chemotherapy}

$\mathrm{P}$ ulmonologists have generally taken a nihilistic view of chemotherapy for the treatment of advanced lung cancer. In a study of beliefs among pulmonologists in the therapeutic treatment of lung cancer, Schroen and colleagues found that only one third of those surveyed believed that chemotherapy conferred a survival benefit for patients with stage IV non-small cell lung cancer and 35\% said they would refer patients with metastatic cancer directly to a hospice without referral to medical oncology. ${ }^{1}$ A survey of British physicians also found that beliefs about the benefits of chemotherapy did not correspond with current medical knowledge and portrayed a more negative impression than the literature would indicate. ${ }^{2}$ There may be legitimate explanations for this difference in perception about outcomes for this patient population. As a group, respiratory physicians may not believe that the small survival benefit achieved with chemotherapy is enough to offset the toxicity associated with treatment. Perhaps we are biased against chemotherapy because we have seen the worst of the worst cases admitted to intensive care units with neutropenic fever and sepsis after receiving chemotherapy. There is also a perception that the additional expense associated with chemotherapy does not outweigh the benefit, particularly as it relates to quality of life.

The Big Lung Trial published in this issue of Thorax answers the questions about survival benefit, toxicity, quality of life, and cost effectiveness. ${ }^{3}$ This is the largest and probably the last trial that will compare supportive care and chemotherapy in the treatment of advanced lung cancer. The trial was well designed, well executed, and was powered to answer these important questions. The findings are generalisable to patients with lung cancer throughout the UK with advanced lung cancer. The criteria for enrolment allowed physicians to treat patients with a number of different chemotherapeutic regimens and accepted patients with a poorer performance status, a subgroup for which we have little information because they have been excluded from many previous trials.

There are three major findings in this study. Firstly, it confirmed the median survival benefit of slightly more than 2 months reported in a previous metaanalysis of chemotherapy for advanced lung cancer. ${ }^{4}$ More important to patients, however, may be the comparison of 1 and 2 year survival; $29 \%$ of those treated with chemotherapy were alive at 1 year compared with $20 \%$ in the supportive care arm, and 2 year survival was doubled in the chemotherapy arm from $5 \%$ to $10 \%$. Secondly, while quality of life did not appear to improve substantially in patients treated with chemotherapy, it did not deteriorate-a finding that may come as a surprise to some. The third major finding of this study is that, while the cost of providing chemotherapy was higher than supportive care, the increased expense was offset by the survival gain and is quite reasonable when compared with other healthcare interventions.

Should these findings persuade pulmonologists to refer patients routinely for chemotherapy for advanced or metastatic lung cancer? Clearly the benefit remains small and the toxicity remains real (in this study $4 \%$ of patients died from treatment related toxicity). Carney $^{5}$ has suggested that we have reached a plateau in the benefits that will arise from chemotherapy, and the lack of meaningful improvement in cure rates with a myriad of different chemotherapy regimens over the last 30 years would seem to confirm this.

When such a decision has to be made, where the benefit is small and toxicity is present, one possible approach is to assess patients' preferences. The literature in this area reveals that patients have a wide variation in their preferences for chemotherapy for advanced lung cancer. In one study patients varied from accepting chemotherapy for 1 week of survival benefit to not accepting treatment for survival benefit of more than 2 years. ${ }^{6}$ Patients had logical-if not at times improbable-reasons for their preferences. The patient who chose treatment for 1 week of survival benefit stated that lung cancer could be cured during that week and he would not want to miss the opportunity for cure. Another would not accept treatment even for a 2 year survival benefit, stating that he had lived a good life and did not want anything to interfere with whatever time he had left. Still another would accept treatment for a 1 month survival gain because he had a child getting married in that month and wanted to survive long enough to reach that important milestone for his family. ${ }^{6}$ It is impossible to predict which patients will choose what treatment before these conversations. Perhaps the best approach to this problem is a shared decision making model where the physician provides the patient with full disclosure regarding the risks and benefits of chemotherapy including discussions of survival, quality of life, toxicity, and patient expectations. This study provides the best information to date regarding the data necessary for good decision making. Upon completion of these discussions the decision for treatment should reside with the patient with input from his or her physician. In this context, patients can decide whether the glass is half empty or half full. Either way, the decision will have been the right one for them.

Thorax 2004;59:821. doi: 10.1136/thx.2004.025916

Correspondence to: $\operatorname{Dr} G$ Silvestri, Associate Professor of Medicine, The Medical University of South Carolina, Charleston, SC 29425, USA; silvestri@musc.edu

\section{REFERENCES}

1 Schroen AT, Detterbeck FC, Crawford R, et al. Beliefs among pulmonologists and thoracic surgeons in the therapeutic approach to non-small cell lung cancer. Chest 2000;1 18:129-37.

2 Spiro SG. Clinical trials in lung cancer: nihilism versus enthusiasm. Thorax 1997;52:598-604.

3 Spiro SG, Rudd RM, Souhami RL, et al. Chemotherapy versus supportive care in advanced non-small cell lung cancer: improved survival without detriment to quality of life. Thorax 2004;59:828-36.

4 Non-Small Cell Lung Cancer Collaborative Group. Chemotherapy in non-small cell lung cancer:a meta-analysis using updated data on individual patients from 52 randomised clinical trials. BMJ 1995;311:899-909.

5 Carney DN. Lung cancer: time to move on from chemotherapy. N Engl J Med 2002;346:126-7.

6 Silvestri G, Pritchard R, Welch $\mathrm{H}$. Preferences for chemotherapy in patients with advanced non-small cell lung cancer: descriptive study based on scripted interviews. BMJ 1998;317:771-5. 


\section{The HRCT scan pursuing real life pathology}

\section{R A Stockley}

\section{HRCT scanning brings a new dimension to studies of COPD}

T he pathogenesis of chronic obstructive pulmonary disease (COPD) is widely considered to be the result of uncontrolled pulmonary inflammation. This is based on the original concept of a protease/antiprotease imbalance leading to peripheral tissue destruction and the development of emphysema. The premature development of emphysema in $\alpha_{1}$-antitrypsin deficiency gave rise to this hypothesis and led to an increasing field of research in the 1970s investigating the inflammation in emphysema using bronchoalveolar lavage. In addition, a series of in vitro experiments investigated the ability of enzymes to produce emphysema-like lesions and its prevention by proteinase inhibitors. ${ }^{1}$ More recently the smoking mouse and a series of gene knock-out and transgenic animals has explored not only the role of proteinases and inflammatory cells, but also proinflammatory cytokines, adhesion molecules, and growth factors in the development of emphysema. ${ }^{2}$

The study of upper airway secretions has indicated that inflammation is also present at this site, and several studies have demonstrated a proteinase/antiproteinase imbalance ${ }^{3}$ that is likely to influence the nature of airways disease, including development of bronchiectasis, mucus hypersecretion, and disturbances of mucociliary clearance. ${ }^{5}$ However, many patients do not expectorate spontaneously, and hence the process of sputum induction was applied to obtain samples from the upper airways in patients with COPD, as defined by the presence of airways obstruction. These studies have led to a change in direction concerning the important cellular and inflammatory proteins that are key to the pathogenesis of COPD.

However, the research field has lost sight of the fact that COPD is a multicomponent multi-compartment disease. The key defining feature is airflow obstruction that is largely irreversible. This physiological abnormality may reflect obliteration of the small airways by oedema, mucus plugging and fibrosis, as well as collapse on expiration due to loss of supporting elastin attachments which is a feature of emphysema. Whereas the small airway mucus, oedema and fibrosis represent inflammation in the airways, the loss of connective tissue supporting structures is related to interstitial inflammation and the development of emphysema.

It is possible with pathological specimens to relate the emphysema to inflammation in cross sectional studies, ${ }^{6}$ but the ability to relate structural changes to inflammation in vivo and, in particular, in longitudinal studies has been impossible to date.

The development of HRCT scanners has brought a new dimension to studies of COPD. The scanner acts as a densitometer and reconstruction provides a visual image that enables the viewer to identify low attenuation areas consistent with the loss of lung tissue that accompanies emphysema. In addition, the contrast between the solid bronchial walls and the air within the lumen enables the bronchi to be visualised with a diameter as low as $1 \mathrm{~mm}$. The pattern of low density areas enables a diagnosis of centrilobular and panacinar emphysema to be made with reasonable accuracy (fig 1). Furthermore, the presence of dilated airways is now the gold standard for the diagnosis of bronchiectasis. ${ }^{7}$ When such studies are applied to patients with a diagnosis of COPD, it is clear that bronchiectasis is common (approximately $25 \%$ of patients) but that, even in severe airflow obstruction, emphysema is often not visually identified. ${ }^{8}$ A further advantage of HRCT scanning is that densitometric analysis allows a quantitative measure of emphysema to be made, and this matches well with the macroscopic and microscopic assessment of pathological specimens. ${ }^{9}$ This methodology therefore provides a real opportunity to follow the progression of emphysema in vivo.

However, the density of lung tissue is not only influenced by the presence of emphysema but also by the level of inspiration. Thus, the quantification of emphysema can be incorrectly estimated by the density unless the level of inspiration is controlled. This is a particular problem on the expiratory film when abnormalities in the small airways result in premature closure and hence air trapping. The retained air remains hypodense and can become more apparent as the emptying normal lung that surrounds it becomes more dense. The degree of air trapping may thus be independent of the presence of emphysema and, for this reason, full inspiratory films are best to quantify the emphysematous pathology.

Despite this apparent problem, the expiratory scan can be more informative about the pathological processes taking place than the inspiratory scan. In the paper by O'Donnell and colleagues in this issue of Thorax, ${ }^{10}$ the authors have used parameters derived from the inspiratory and expiratory HRCT scans to assess the relationship between peripheral airway dysfunction and physiological abnormalities and airway neutrophilia in COPD.

The patients studied had a wide range of forced expiratory volume in 1 second $\left(\mathrm{FEV}_{1}\right)$ abnormality. By definition, this shows progressive impairment within broad groups of the GOLD staging. Similarly, the flow rate at $50 \%$ expiration $\left(\mathrm{MEF}_{50 \%}\right)$ showed progressive impairment across the groups, as did
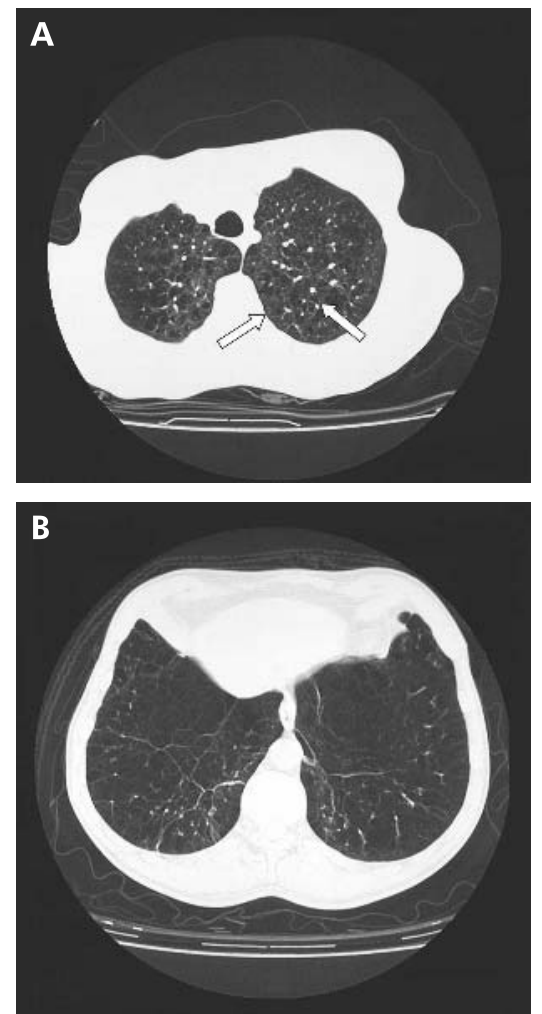

Figure 1 HRCT scans of emphysema showing (A) a patient with centrilobular emphysema with typical patchy low density areas (arrowed) and (B) a more diffuse pattern typical of panacinar emphysema in a patient with $\alpha_{1}$-antitrypsin deficiency. 
the carbon monoxide transfer factor (Tlco, a measure of gas distribution and uptake). On the other hand, the carbon monoxide transfer coefficient (KCO), which is a more direct measure of loss of alveolar gas exchanging surface (emphysema), showed no progressive impairment from stage 0 to stage II-IV, which is consistent with the emphysema being reported as minimal to extensive even in the severe group.

The authors analysed the HRCT scan in two ways-firstly, the expiratory to inspiratory lung density ratio which reflects the degree of air trapping and hence small airways disease and, secondly, the proportion of low density areas on the inspiratory scans which reflects the amount of emphysematous tissue. Using the latter data, there was no correlation with KCO which is at variance with other studies of patients with emphysema. ${ }^{11}{ }^{12}$ This again suggests that the results are influenced by the mild degree of emphysema seen in many of the patients. Indeed, the average proportion of low density areas seen in the three groups on the inspiratory scan $(5.8-11.4 \%$ in table 1 of the paper $^{10}$ ) confirms this to be the case. Of particular importance is the failure of the neutrophil counts to correlate with either the CT or physiological assessment of emphysema. This suggests that samples obtained by sputum induction do not reflect the pathological processes at the alveolar level which reflect the development of emphysema, emphasising a compartmentalisation of inflammation and pathology.
On the other hand, the expiratory CT parameters and the expiratory to inspiratory ratios showed good correlation with tests of airflow obstruction and air trapping but not with gas transfer. The degree of neutrophilia of the induced sputum also showed good correlations with these measures, suggesting that the inflammation harvested by this technique reflects pathological processes at the level of the small airways.

This study has important implications. Although associations in cross sectional studies do not reflect cause and effect, the findings of this study suggest that sputum induction does not reveal pathogenic processes involved in emphysema but rather the factors influencing or influenced by small airways pathology. It is therefore more critical that future studies should clarify the phenotype of the patients being studied so that conceptual quantum leaps in pathophysiology are not made. Standardisation of algorithms used in the CT scan and more radiopathological comparisons and analytical techniques offer a real opportunity to study the pathophysiological processes involved in structural changes within the lung and, more importantly, their progression or response to treatment.

\section{Thorax 2004;59:822-823.}

doi: 10.1136/thx.2004.029785

Correspondence to: Dr R A Stockley, Department of Medicine, Queen Elizabeth Hospital, Edgbaston, Birmingham B15 2TH, UK; r.a.stockley@bham.ac.uk

\section{Pi MZ and COPD: will we ever know?}

\section{N Seersholm}

Based on the current evidence, there is no reason to believe that $\mathrm{Pi} M Z$ individuals have an increased risk of developing lung disease as long as they do not smoke

s Pi MZ a risk factor for the development of chronic obstructive pulmonary disease (COPD)? That is the question many authors have tried to answer during the last decades, but the results of published studies are still conflicting.

A very high percentage of patients with COPD have been smokers, but not all smokers develop COPD. There must be other contributing factors and, with a Pi MZ prevalence of $3-5 \%$ in many
Western countries, it is relevant to determine whether this genotype is an additional risk factor for COPD. ${ }^{1}$ Furthermore, if a dose-response relation exists, it is biologically plausible since plasma levels of $\alpha_{1}$-antitrypsin (AAT) are reduced to about $60 \%$ in $\mathrm{Pi} \mathrm{MZ}$ subjects compared with those with the normal Pi MM genotype, and Pi Z individuals with very low levels of AAT have a significantly increased risk for emphysema.

\section{REFERENCES}

1 Stockley RA. Biochemical and cellular mechanisms in chronic obstructive pulmonary disease. In: Calverley P, Pride N, eds. Chronic obstructive pulmonary disease. London: Chapman and Hall, 1995:93-133.

2 Sullivan AL, Stockley RA. Proteinases in COPD. In: Hansell TT, Barnes PJ, eds. Recent advances in the pathophysiology of COPD. Basel: Birkhauser Verlag, 2004:75-99.

3 Hill AT, Campbell EJ, Bayley DL, et al. Evidence for excessive inflammation during an acute exacerbation of chronic obstructive pulmonary disease in patients with alpha-1 antitrypsin deficiency (PiZ). Am J Respir Crit Care Med 1999; 160:1968-75.

4 Stockley RA, Burnett D. Alpha-1 antitryspin and leucocyte elastase in infected and non-infected sputum. Am Rev Respir Dis 1979;120:1081-6.

5 Stockley RA. Neutrophils and the pathogenesis of COPD. Chest 2002;121:151-5S.

6 Hogg JC, Chu F, Utokaparch S, et al. The nature of small-airway obstruction in chronic obstructive pulmonary disease. N Engl J Med 2004:350:2645-53.

7 Hansell DM, Bronchiectasis In: Webb WR, ed. Imaging in obstructive pulmonary disease. Philadelphia: WB Saunders, 1998:107-28.

8 O'Brien C, Guest PJ, Hill SL, et al. Physiological and radiological characterisation of patients diagnosed with chronic obstructive pulmonary disease in primary care. Thorax 2000;55:635-42.

9 Gevenois PA, De-Maertelaer V, De Vuyst P, et al. Comparison of computed density and macroscopic morphometry in pulmonary emphysema. Am J Respir Crit Care Med 1995; 152:653-7.

10 O'Donnell RA, Peebles C, Ward JA, et al. Relationship between peripheral airway dysfunction, airway obstruction, and neutrophilic inflammation in COPD. Thorax 2004;59:837-42.

11 Dowson L, Guest PJ, Hill SL, et al. High resolution computed tomography scanning in alpha-1 antitryspin deficiency: relationship to lung function and health status. Eur Respir $J$ 2001;17:1097-104.

12 Consella M, Muller NL, Abud RT, et al. Quantitation of emphysema by computed tomography using a 'density mask' programme and correlation with pulmonary function tests. Chest 1990;97:315-21.

There are a number of reasons for the discrepancy between the studies conducted on this subject. Firstly, smoking is a very significant confounder in the development of emphysema which is almost impossible to control for. Secondly, many studies have been subject to various types of bias, particularly selection bias. Thirdly, only a few studies have been sufficiently large to produce a significant result and very few studies have been population based. Finally, the phenotypic appearance of the Pi MZ genotype may be heterogenic.

In the studies of a causal relationship of a risk factor (Pi MZ genotype) and the development of a disease (COPD) there are two types of designs: casecontrol studies and cohort studies. Cohort studies can be divided into cross sectional studies and follow up studies.

In case-control studies the researchers identify a group with COPD, find a proper control group without the disease, and compare the prevalence of the Pi MZ genotype between the two 
groups. The major problems are finding a proper control group from the same population as the cases and selection bias. For example, if a person is known to have the Pi MZ genotype, he may be more likely to have his lungs examined because of Pi Z patients with lung disease in his family. If his lung function is reduced, he suddenly becomes a case instead of a control.

A cohort study compares either the prevalence of COPD in a cross sectional setting or the incidence of COPD in a longitudinal setting of a group of Pi MZ individuals with a matched control group which can be derived from the general population. The longitudinal design is often superior to the casecontrol design but is much more expensive and time consuming and it may be underpowered. In a longitudinal cohort study it is critical to start counting person years from the date the genotype was established and only to use data collected afterwards. Some authors have used data collected before this date in the calculation of the rate of decline in forced expiratory volume in 1 second $\left(\mathrm{FEV}_{1}\right)$, and it can produce biased results. ${ }^{2}$ The best cohort studies are population based with large sample sizes, long follow up times, and no selection bias, but only a few have been conducted on Pi MZ and COPD. ${ }^{3}$

When published studies are small and inadequate for drawing a firm conclusion, a meta-analysis may be the solution. In this issue of Thorax Hersh and colleagues have combined published case-control studies and cross sectional cohort studies in a meta-analysis and tried to determine whether Pi MZ is a risk factor for COPD. ${ }^{4}$ Their conclusion is the same as that of previous review papers-namely, that case-control studies are in favour of an increased risk and cohort studies are not. ${ }^{5}$ Their final conclusion is that Pi MZ individuals have a small increased risk for COPD or a fraction of Pi MZ individuals carry a larger risk.

Seersholm et al came to the same conclusion in a study of Pi MZ individuals identified through relatives of Pi Z patients either because of lung symptoms (index cases) or through family screening. ${ }^{6}$ The study showed an increased risk for hospitalisation for COPD in Pi MZ individuals, but subanalysis showed the increased risk to be present only in Pi MZ individuals who were close relatives to $\mathrm{Pi} \mathrm{Z}$ index patients.

If only a percentage of $\mathrm{Pi} \mathrm{MZ}$ individuals are at increased risk for COPD, they must carry additional risks-either environmental, genetic, or both. Smoking is the major environmental confounder and only five of the 16 studies included in the meta-analysis corrected for smoking. The pooled odds ratio for these five studies was not significantly increased after adjustment for smoking habits. It is tempting to conclude that the apparent increased risk for COPD found in Pi MZ individuals is caused by differences in smoking habits and not by the Pi MZ genotype. If this is true, Pi MZ individuals should be more susceptible to start smoking and therefore their smoking habits are determined by their genotype. This is not unlikely if the Pi MZ persons were identified through family screening and thus are subject to selection bias. The vast majority of Pi Z index cases have been smokers and smoking habits are influenced by parents and siblings and thus aggregate in families.?

The difficulty in discriminating between environment and genes is further demonstrated in a recently published study by Svanes and colleagues who concluded that intrauterine and environmental exposure to parental smoking was related to the development of lung disease in adulthood. ${ }^{8}$ It is, however, also possible that modifier genes ( $\mathrm{Z}$ allele or others) were responsible for some of the increased risk for lung disease.

Silverman et al investigated quantitative phenotypes in $52 \mathrm{Pi}$ MZ first degree relatives of Pi Z patients with or without significant airflow obstruction. They found a trend towards lower $\mathrm{FEV}_{1}$ in Pi MZ relatives of Pi Z subjects with airflow obstruction, a trend that could not be explained by differences in smoking habits." A Danish study of $\mathrm{Pi} \mathrm{Z}$ patients found that Pi Z index cases have a worse prognosis than Pi $\mathrm{Z}$ nonindex cases even after controlling for smoking habits, and never smoking non-index cases had no increased mortality compared with the general population. ${ }^{10}$ These studies suggest that other genetic factors contribute to the development of lung disease.

Besides protease inhibitor deficiency alleles, no candidate genes for the development of COPD have yet been identified although several have been proposed-including $\alpha_{1}$-antichymotrypsin, glutathione S-transferase, and tumour necrosis factor $\alpha .{ }^{11}$ Linkage analysis of pedigrees ascertained through probands with severe early onset COPD who had normal AAT levels have shown a susceptibility locus on chromosome 2 and possibly several other genomic regions. ${ }^{12}$

The development of COPD is a complex interaction between environmental exposure and possible many genes, and whether Pi MZ is one of the genotypes remains to be shown. Observational studies and meta-analyses based on them should be interpreted very carefully, particularly in view of the impact of smoking and biased case selection. For example, if the study by Seersholm et al had included Pi MZ relatives of Pi Z index cases only, the conclusion would have been that all Pi MZ individuals are at increased risk of hospitalisation for COPD. The variability of quantitative phenotypes of homozygous AAT patients is ideal for the further study of modifier genes but, because of the rarity of the disease, international collaboration will be necessary.

To determine whether Pi MZ is a risk factor for COPD requires a large population based study with long follow up time. The most recently published study found no accelerated decline in $\mathrm{FEV}_{1}$ in $57 \mathrm{Pi} \mathrm{MZ}$ individuals followed for an average of 15 years, but the study may be underpowered. ${ }^{3}$ In 1991-4 the Copenhagen city heart study genotyped a sample of 9000 individuals from the general population and identified 450 Pi MZ subjects. They have completed questionnaires on smoking habits and have undergone extensive testing including spirometry and, with a follow up time of more than 10 years, the study should soon come up with a sound conclusion. In the meantime, we have to advise individuals with the Pi MZ genotype about their risk for developing lung disease and, based on the current evidence, there is no reason to believe they have an increased risk as long as they do not smoke.

Thorax 2004;59:823-825. doi: 10.1136/thx.2004.024810

Correspondence to: $\operatorname{Dr} N$ Seersholm,

Pulmonary Department Y, Gentofte Hospital, Niels Andersens Vej 65, DK-2900 Hellerup, Denmark; seersholm@dadlnet.dk

\section{REFERENCES}

1 American Thoracic Society/European Respiratory Society. Standards for the diagnosis and management of individuals with alpha- 1 antitrypsin deficiency. Am J Respir Crit Care Med 2003; 168:818-900.

2 Dahl M, Tybjaerg-Hansen A, Lange $P$, et al. Change in lung function and morbidity from chronic obstructive pulmonary disease in alpha-1antitrypsin MZ heterozygotes: a longitudinal study of the general population. Ann Intern Med 2002; 136:270-9.

3 Silva GE, Sherrill DL, Guerra S, et al. A longitudinal study of alpha-1-antitrypsin phenotypes and decline in $\mathrm{FEV}_{1}$ in a community population. Chest 2003;123:1435-40.

4 Hersh CP, Dahl M, Ly NP, et al. Chronic obstructive pulmonary disease in $\alpha_{1}$-antitrypsin Pi MZ heterozygotes: a meta-analysis. Thorax 2004;59:843-9.

5 Feld RD. Heterozygosity of alpha 1-antitrypsin: a health risk? Crit Rev Clin Lab Sci 1989;27:461-81.

6 Seersholm N, Wilcke JT, Kok-Jensen A, et al. Risk of hospital admission for obstructive pulmonary disease in alpha(1)-antitrypsin heterozygotes of phenotype Pi MZ. Am J Respir Crit Care Med 2000;161:81-4. 
7 von Bothmer MI, Mattsson B, Fridlund B. Influences on adolescent smoking behaviour: siblings' smoking and norms in the social environment do matter. Health Soc Care Community 2002;10:213-20.

8 Svanes C, Omenaas E, Jarvis D, et al. Parental smoking in childhood and adult obstructive lung disease: results from the European Community Respiratory Health Survey. Thorax 2004;59:295-302.
9 Silverman EK, Province MA, Rao DC, et al. A family study of the variability of pulmonary function in alpha 1-antitrypsin deficiency. Quantitative phenotypes. Am Rev Respir Dis 1990; 142:1015-21.

10 Seersholm N, Kok-Jensen A, Dirksen A Survival of patients with severe alpha 1 -antitrypsin deficiency with special reference to non-index cases. Thorax 1994:49:695-8.
11 Sandford AJ, Silverman EK. Chronic obstructive pulmonary disease. 1: Susceptibility factors for COPD, the genotype-environment interaction. Thorax 2002;57:736-41.

12 Silverman EK, Mosley JD, Palmer U, et al. Genome-wide linkage analysis of severe, early-onset chronic obstructive pulmonary disease: airflow obstruction and chronic disease: airflow obstruction and chronic 2002; 11:623-32.

\section{Environmental allergen exposure, sensitisation and asthma: from whole populations to individuals at risk}

\section{A Custovic, A Simpson}

To prevent asthma and allergies we need to design interventions appropriate for individual susceptibilities, taking account of both genes and the environment

S ensitisation to inhalant allergens remains a major risk factor for asthma, ${ }^{1}$ but the size of the effect is hotly debated. ${ }^{2} 3$ Several cross sectional studies have suggested a simple dose-response relationship between dust mite allergen exposure and specific sensitisation, both within communities ${ }^{4-7}$ and between communities exposed to differing levels of mite allergens. ${ }^{8}$ The threshold concentration of $2 \mu \mathrm{g}$ Group 1 mite allergen per gram of dust for developing mite sensitisation in children at high risk has been suggested, but a much higher cut off level of $80 \mu \mathrm{g} / \mathrm{g}$ appeared significant in low risk children. ${ }^{4}$ For other allergens the relationship between exposure and sensitisation is less well defined. Several studies in the US inner city areas reported that children are more likely to become sensitised to cockroach with increasing cockroach allergen exposure, ${ }^{9}$ and that high exposure to mouse allergen appears to be associated with an increased prevalence of sensitisation to mouse. ${ }^{10}$ Some studies in older children and adults reported a close relationship between specific allergen sensitisation and current domestic exposure for mite and cockroach, but not cat allergen. ${ }^{511}$ This, together with studies reporting a protective effect of high cat allergen exposure on sensitisation, ${ }^{12}{ }^{13}$ raises the question of whether the dose-response relationship between exposure and sensitisation may be different for different allergens. However, there are remarkably few published data on the longitudinal relationship between allergen exposure and the development of specific sensitisation.

\section{EVIDENCE FROM LONGITUDINAL STUDIES}

Several observational birth cohort studies investigating risk factors for the development of allergen sensitisation and asthma have measured allergen levels in dust samples collected in early life to examine the association between allergen exposure and the development of specific sensitisation. The studies were based in Germany, ${ }^{14}$ Sweden, ${ }^{15}$ Holland, ${ }^{16}$ and the UK (Manchester ${ }^{17}$ and Ashford cohorts ${ }^{18}$ ). While this is the optimal study design for conditions which manifest early in life and progress into adulthood, these studies are difficult and expensive to run and it takes many years to obtain meaningful results.

Following several reports by the German Multicenter Allergy Study (MAS-90), ${ }^{19}{ }^{20}$ in this issue of Thorax Cullinan et al become only the second birth cohort to report the exposureoutcomes relationship presenting their results for sensitisation and atopic wheeze at age 5 years in 552 children. $^{18}$ This cohort from Ashford, UK is truly population based; the investigators approached every woman presenting for antenatal care to three general practices in the area. By skin prick testing the children at the age of 5 years to three common allergens (mite, cat and pollen) they identified a rate of allergic sensitisation of $17 \%$, a figure similar to the $19.6 \%$ reported in the Isle of Wight cohort at age 4 years. ${ }^{21} \mathrm{~A}$ total of $7 \%$ of the children had atopic wheeze. Mite and cat allergen levels were measured in the living room floor at one time point ( 8 weeks after birth) and the levels were similar to other contemporaneous data from the UK. For the whole population there was no linear doseresponse relationship between mite and cat allergen levels and the respective specific sensitisations. For mite, there was an increase in the proportion of sensitised children on moving from the 1st to the 2nd quintile of exposure, after which rates of sensitisation appeared to tail off. For cat, sensitisation increased steadily from the 2 nd to the 4 th quintile and then tailed off. While this pattern was not significantly altered when children with paternal atopy were considered separately, there was a significant interaction between paternal atopy and mite exposure with a considerably higher proportion of high risk children being sensitised at any given quintile of exposure (except for the lowest).

These results are markedly different from those in the MAS-90 study. ${ }^{19}{ }^{20}$ The population sample in the German study was larger (939 at age 7 years) and differs from the Ashford cohort as it is enriched with high risk children. Rates of sensitisation were compared between children in the lowest and highest quartiles of mite allergen exposure. At the age of 7 those in the highest quartile were significantly more likely to be sensitised than those in the lowest quartile $(\sim 14 \% v \sim 4 \%)$. A similar effect was seen for cat allergen exposure and sensitisation to cat.

How do we assimilate these two apparently different sets of results? It is likely that the relationship between exposure and sensitisation differs markedly between children at high risk and those at low risk of allergic sensitisation. The MAS-90 study was weighted with high risk children and the strongest dose-response relationship was seen in this group. ${ }^{19}$ On the other hand, the study by Cullinan et al is more representative of the general population with allergen exposure likely to be of little relevance for the majority of subjects. In a population of this composition and size with a modest (by Australian 
standards) range of mite allergen levels, the dose-response relationship is likely to appear flat. Thus, a dose-response relationship between mite allergen exposure and sensitisation is easier to demonstrate in larger populations weighted with high risk children.

How about the relationship between allergen exposure and asthma development? The Poole cohort described by Sporik et $a l^{22}$ is the only longitudinal study to date to report a significant relationship between early life exposure to dust mite allergen and asthma at the age of 11 years in a small group of 69 high risk children. Most other studies were unable to reproduce these results. Burr et $a^{23}$ reported no relationship between physician diagnosed asthma or wheezing at age 7 years and dust mite allergen levels in the first or seventh year of life in a prospective study of 453 children. Similarly, in the MAS-90 study, despite a strong association between sensitisation to mite and cat allergens and wheezing and the significant relationship between mite and cat allergen exposure and specific sensitisation, there was no consistent dose-response relationship between allergen exposure and doctor diagnosed asthma, wheezing within the last 12 months, or wheezing ever. ${ }^{20}$

\section{LESSONS FROM INTERVENTION STUDIES}

Intervention studies focusing on high risk children that use environmental control aimed at reducing allergen exposure from or before birth may help to explain the relationship between allergen exposure and clinical outcomes. Six ongoing studies have published results to date.

\section{Isle of Wight Study}

This study implemented an intervention designed to reduce exposure to inhalant and food allergens as part of a primary prevention programme. At the age of 1 year there was a reduction in sensitisation and in wheeze in the intervention group, ${ }^{24}$ but the differences in respiratory symptoms disappeared by age 2 and 4 years. ${ }^{25}{ }^{26}$ At the age of 8 sensitisation to mite in the intervention group was reduced by more than $50 \%{ }^{27}$ Furthermore, children in the active group were significantly less likely to have current wheeze, nocturnal cough, and wheeze with bronchial hyperresponsiveness.

\section{Canadian Asthma Primary Prevention Study (CAPPS)}

A multifaceted intervention including measures to reduce exposure to inhalant and food allergens was used. ${ }^{28}$ At the age of 1 year there was a significant reduction in probable asthma and rhinitis in the active group..$^{29}$ At the age of 2 years significantly fewer children had asthma in the intervention group than in the control group (16.3\% $v 23 \%)$ but there was no difference in sensitisation. ${ }^{30}$

\section{Study on the Prevention of Allergy in Children in Europe (SPACE)}

In this study the multifaceted intervention was directed towards both inhalant and food allergens. Results reported at the age of 1 year showed a reduction in mite sensitisation but no difference in the proportion of children who had wheezed (21\% both groups). ${ }^{31}$

\section{Childhood Asthma Prevention Study (CAPS)}

The Childhood Asthma Prevention Study in Sydney, Australia reported no effect of mite allergen avoidance on sensitisation rates at the age of 18 months. ${ }^{32}$ However, by 3 years of age mite sensitisation was significantly reduced in the active mite allergen avoidance group. ${ }^{33}$ Respiratory symptoms were not affected by mite allergen avoidance but there appeared to be more eczema in this group.

\section{Prevention and Incidence of Asthma and Mite Allergy Study (PIAMA)}

The Prevention and Incidence of Asthma and Mite Allergy Study in the Netherlands achieved significantly lower mite allergen levels in the active group than in the control group 1 year after the introduction of intervention measures, but the baseline exposure was very low. ${ }^{34}$ Children in the active group appeared less likely to have had recurrent wheeze during the first year of life, but the only significant difference between groups was a reduction in night time cough without a cold in the active group at age 2 years. ${ }^{35}$ There was no difference in sensitisation between the groups.

\section{Manchester Asthma and Allergy Study (MAAS)}

This study used a much more stringent environmental control regime than other primary prevention studies. ${ }^{36} \mathrm{~A}$ significant and sustained reduction in allergen exposure was achieved in the active group. ${ }^{36}{ }^{37}$ At 1 year of age there was slightly more sensitisation in the active group (17\% $v 14 \%)$ but this did not reach statistical significance. ${ }^{38}$ Asthma-like symptoms were consistently lower in the intervention group, and this reached significance for attacks of severe wheeze with shortness of breath, prescribed medication for wheezy attacks, and wheeze after playing or exertion. However, counter-intuitive results were reported at the follow up at 3 years of age, suggesting that stringent environmental control was associated with increased risk of sensitisation to dust mite but better lung function. ${ }^{39}$

How did the children become sensitised to mite allergens if they had low exposure at home? Even with a complex intervention there remains a residual mite allergen exposure within the home. Additional exposure in the homes of relatives or outside the home may lead to intermittent exposure, which may favour sensitisation in comparison with continuous exposure. ${ }^{39}$

\section{CONCLUSIONS}

Clinical outcomes reported from different observational and intervention studies appear inconsistent and often confusing. What are the implications of the study by Cullinan et al for the design of primary prevention strategies? These results emphasise the point that any single primary prevention strategy will not be applicable to the whole population, but only to individuals within the population with a particular susceptibility. This raises the important question of how one determines susceptibility. To date most investigators have used parental history of allergic disease and allergen sensitisation to assign risk. There is an ongoing debate about the relative role of maternal and paternal disease, with most studies (but, interestingly, not the Ashford cohort ${ }^{18}$ ) finding an increased influence of maternal disease. However, assigning risk based on parental history of allergy is insufficiently precise and unsatisfactory, and we have to find more specific markers. Many research groups are trying to identify genetic polymorphisms which confer an increase in risk for allergen sensitisation and for asthma with limited success. This is partly due to the difficulties in phenotype definition and the fact that genetics research has rarely taken account of the relevant environmental exposures. A particular genetic polymorphism may only be associated with an increase (or decrease) in risk in those exposed to a specific environmental factor. In order to understand risk factors for asthma and allergies, one needs to study the interaction between the inherited risk and the environment by measuring both. Future primary prevention studies aimed at prevention of asthma and allergies will be informed by studies of gene-environment interactions. We need to move away from the concept of blanket advice aimed at the whole population to tailor made individualised measures targeting individuals with specific susceptibilities who will benefit from a particular intervention. 
Thorax 2004;59:825-827.

doi: 10.1136/thx.2004.027334

\section{Authors' affiliations}

A Custovic, A Simpson, North West Lung Centre, Wythenshawe Hospital, Manchester M23 9LT, UK

Correspondence to: Professor A Custovic North West Lung Centre, Wythenshawe Hospital, Southmoor Road, Manchester M23

9LT,UK; a.custovic@man.ac.uk

\section{REFERENCES}

1 Simpson BM, Custovic A, Simpson A, et al. NAC Manchester Asthma and Allergy Study (NACMAAS): risk factors for asthma and allergic disorders in adults. Clin Exp Allergy 2001;31:391-9.

2 Pearce N, Pekkanen J, Beasley R. How much asthma is really attributable to atopy? Thorax 1999;54:268-72

3 Pearce N, Douwes J, Beasley R. Is allergen exposure the major primary cause of asthma? Thorax 2000;55:424-31.

4 Kuehr J, Frischer T, Meinert R, et al. Mite allergen exposure is a risk for the incidence of specific sensitisation. J Allergy Clin Immuno 1994:94:44-52.

5 Sporik R, Squillace SP, Ingram JM, et al. Mite, cat and cockroach exposure, allergen sensitisation and asthma in children: a case-control study of three schools. Thorax 1999:54:675-80.

6 Lau S, Falkenhorst G, Weber A, et al. High miteallergen exposure increases the risk of sensitization in atopic children and young adults. J Allergy Clin Immunol 1989;84:718-25.

7 Huss K, Adkinson NF Jr, Eggleston PA, et al. House dust mite and cockroach exposure are strong risk factors for positive allergy skin test responses in the Childhood Asthma Management Program. J Allergy Clin Immunol 2001;107:48-54

8 Peat JK, Tovey E, Toelle BG, et al. House dust mite allergens. A major risk factor for childhood asthma in Australia. Am J Respir Crit Care Med 1996;153:141-6.

9 Eggleston PA, Rosenstreich D, Lynn $\mathrm{H}$, et al. Relationship of indoor allergen exposure to skin test sensitivity in inner-city children with asthma. J Allergy Clin Immunol 1998;102:563-70.

10 Phipatanakul W, Eggleston PA, Wright EC, et al. Mouse allergen. II. The relationship of mouse allergen exposure to mouse sensitization and asthma morbidity in inner-city children with asthma. J Allergy Clin Immuno 2000; 106: 1075-80.

11 Custovic A, Simpson BM, Simpson A, et al. Current mite, cat and dog allergen exposure, pet ownership and sensitization to inhalant allergens in adults. J Allergy Clin Immunol 2003;111:402-7.

12 Custovic A, Hallam CL, Simpson BM, et al. Decreased prevalence of sensitization to cats with high exposure to cat allergen. J Allergy Clin Immunol 2001;108:537-9.

13 Platts-Mills T, Vaughan J, Squillace $S$, et al. Sensitisation, asthma, and a modified Th2 response in children exposed to cat allergen: a population-based cross-sectional study. Lancet 2001;357:752-6.

14 Nickel R, Lau S, Niggemann B, et al. Messages from the German Multicentre Allergy Study. Pediatr Allergy Immunol 2002; 13(Suppl 15): 7-10.

15 Wickman M, Kull I, Pershagen G, et al. The BAMSE Project: presentation of a prospective longitudinal birth cohort study. Pediatr Allergy Immunol 2002;13(Suppl 15):11-13.

16 Brunekreef B, Smit J, Jongste J, et al. The prevention and incidence of asthma and mite allergy (PIAMA) birth cohort study: design and first results. Pediatr Allergy Immunol 2002;13(Suppl 15):55-60.

17 Custovic A, Simpson BM, Murray CS, et al. The National Asthma Campaign Manchester Asthma and Allergy Study. Pediatr Allergy Immunol 2002;13(Suppl 15):32-7.

18 Cullinan P, MacNeill SJ, Harris JM, et al. Early allergen exposure, skin prick responses and atopic wheeze at age five in English children: a cohort study. Thorax 2004;59:855-61.

19 Wahn U, Lau S, Bergmann R, et al. Indoor allergen exposure is a risk factor for sensitisation during the first three years of life. J Allergy Clin Immunol 1997;99:763-9.

20 Lau S, Illi S, Sommerfeld C, et al. Early exposure to house dust mite and cat allergens and development of childhood asthma: a cohort study. lancet 2000;356:1392-7.

21 Arshad SH, Tariq SM, Matthews S, et al. Sensitisation to common allergens and its association with allergic disorders at age 4 years: a whole population birth cohort study. Pediatrics 2001;108:e33.

22 Sporik R, Holgate ST, Platts-Mills TA, et al. Exposure to house-dust mite allergen (Der $\mathrm{pl}$ ) and the development of asthma in childhood. A prospective study. N Engl J Med 1990;323:502-7.

23 Burr ML, Limb ES, Maguire MJ, et al. Infan feeding, wheezing, and allergy: a prospective study. Arch Dis Child 1993;68:724-8.

24 Arshad SH, Matthews S, Gant C, et al. Effect of allergen avoidance on development of allergic disorders in infancy. Lancet 1992;339:1493-7.

25 Hide DW, Matthews S, Matthews L, et al. Effect of allergen avoidance in infancy on allergic manifestations at age 2 years. J Allergy Clin Immunol 1994;93:842-6.

26 Hide DW, Matthews S, Tariq S, et al. Allergen avoidance in infancy and allergy at 4 years of age. Allergy 1996;51:89-93.
27 Arshad SH, Bateman B, Matthews SM. Primary prevention of asthma and atopy during childhood by allergen avoidance in infancy: a randomized controlled study. Thorax 2003;58:489-93.

28 Chan-Yeung M, Ferguson A, Dimich-Ward $\mathrm{H}$ et al. Effectiveness and compliance to intervention measures in reducing house dust and cat allergen levels. Ann Allergy Asthma Immunol 2002;88:52-8

29 Chan-Yeung M, Manfreda J, Dimich-Ward $\mathrm{H}$ et al. A randomized controlled study on the effectiveness of a multifaceted intervention program in the primary prevention of asthma in high-risk infants. Arch Pediatr Adolesc Med 2000; 154:657-63

30 Becker A, Watson W, Ferguson A, et al. The Canadian Asthma Primary Prevention Study: outcomes at 2 years of age. J Allergy Clin Immunol 2004;113:650-6.

31 Halmerbauer G, Gartner C, Schierl M, et al. Study on the Prevention of Allergy in Children in Europe (SPACE): allergic sensitization at 1 year of age in a controlled trial of allergen avoidance from birth. Pediatr Allergy Immunol 2003; 14:10-17.

32 Mihrshahi S, Peat JK, Marks GB, et al. Eighteenmonth outcomes of house dust mite avoidance and dietary fatty acid modification in the Childhood Asthma Prevention Study (CAPS) J Allergy Clin Immunol 2003;111:162-8.

33 Peat JK, Mihrshahi S, Kemp AS, et al. Three yea outcomes of dietary fatty acid modification and house dust mite reduction in the Childhood Asthma Prevention Study (CAPS). J Allergy Clin Immunol 2004 (in press).

34 van Strien $\mathbf{R}$, Koopman L, Kerkhof $M$, et al. Mattress encasings and mite allergen levels in the prevention and incidence of asthma and mite allergy study. Clin Exp Allergy 2003;33:490-5.

35 Koopman LP, van Strien R, Kerkhof $M$, et al. Placebo-controlled trial of house dust miteimpermeable mattress covers: effect on symptoms in early childhood. Am J Respir Crit Care Med 2002; 166:307-13

36 Custovic A, Simpson BM, Simpson A, et al. Manchester Asthma and Allergy Study: low allergen environment can be achieved and maintained during pregnancy and in early life. J Allergy Clin Immunol 2000;105:252-8.

37 Simpson A, Simpson B, Custovic A, et al. Stringent environmental control in pregnancy and early life: the long term effects on mite, cat and dog allergen. Clin Exp Allergy 2003;33:1183-9.

38 Custovic A, Simpson BM, Simpson A, et al Environmental control in pregnancy and early life: effect on respiratory symptoms and atopy during the first year of life. Lancet 2001:31:1194-204.

39 Woodcock A, Lowe LA, Murray CS, et al Early life environmental control: effect on symptoms, sensitization and lung function at age 3 years. Am J Respir Crit Care Med 2004;170:433-9.

\section{Lung Alerts: Call for Contributors}

Lung Alerts were introduced in Thorax in January 2003. We aim to increase the educational content of the journal by providing rapid, concise (approximately 250 words) summaries of papers published in general medical or non-respiratory specialist journals that are of interest to the readership of Thorax. Articles are selected by the Editors and commissioned from a database of contributors. To remain topical, completed submissions must be returned to us quickly, usually within seven working days.

We are currently looking to expand our list of contributors and would particularly welcome applications from doctors in training grades. To apply, please forward your name, contact e-mail, position, institution, and any specialist interests to the Lung Alert Editors at either of the addresses given below. 